\title{
Analysis of microsatellite instability and loss of heterozygosity in breast cancer with the use of a well characterized multi- plex system
}

\author{
Jolanta Powierska-Czarny ${ }^{1 凶}$, Danuta Miścicka-Śliwka ${ }^{2}$, Jakub Czarny ${ }^{2}$, Tomasz \\ Grzybowski $^{2}$, Marcin Woźniak ${ }^{2}$, Gerard Drewa ${ }^{1}$, Włodzimierz Czechowicz ${ }^{3}$ \\ and $\operatorname{Jan} \mathrm{Sir}^{3}$
}

\author{
${ }^{1}$ Department of Human Biology and ${ }^{2}$ Forensic Medicine Institute, The Ludwik Rydygier \\ Medical University of Bydgoszcz, Bydgoszcz, Poland; ${ }^{3}$ Regional Center of Oncology, \\ Bydgoszcz, Poland
}

Received: 10 December, 2003; revised: 09 July, 2003; accepted: 18 August, 2003

Key words: short tandem repeats, microsatellite instability, breast cancer, multiplex DNA typing

\begin{abstract}
Analysis of microsatellite instability (MI) and loss of heterozygosity (LOH) is recommended for screening patients with sporadic and hereditary malignancies. This study shows an application of a fluorescent hexaplex PCR system for microsatellite typing on A.L.F. DNA Sequencer (Pharmacia Biotech). This technique detects changes in microsatellites providing a time-efficient, reliable and accurate method for MI and LOH analyses. The Fragment Manager software was used for automated size calculation and quantitation of DNA fragments, enabling rapid and precise measurement of allelic ratios. We examined 70 breast cancer and 70 control DNA specimens, classified all the patterns of microsatellite alterations, and set up MI and LOH assessment criteria for the automated multiplex fluorescent method.
\end{abstract}

The detection of genomic instability is an important step in molecular analysis of tumorogenesis. Somatic alterations in microsatellite sequences due to a deletion or an insertion of one or more repeat units have been termed "microsatellite instabilities" (MI or
MIN). Microsatellite instability, referred to as replication error (RER) phenotype, is associated with defects in the DNA mismatch-repair machinery (Fishel et al., 1993; Bronner et al., 1994). In hereditary nonpolyposis colorectal carcinoma (HNPCC), this instability

\footnotetext{
${ }^{\circledR}$ Corresponding author: Jolanta Powierska-Czarny, The Ludwik Rydygier Medical University of Bydgoszcz, Powstańców Wielkopolskich 44/39, 85-090 Bydgoszcz, Poland; tel: (48 525) 853 658; e-mail: jolanta_powierska@o2.pl

Abbreviations: AMG, amelogenin; IDC, invasive ductal carcinoma; LOH, loss of heterozygosity; MI, microsatellite instability; STR, short tandem repeat.
} 
was shown to be caused by a germline mutation in mismatch-repair genes (Aaltonen et al., 1993; Papadopoulos et al., 1994). MI has been detected in a wide variety of human neoplasmic tumors, both hereditary and sporadic, and is used as a diagnostic criterion for mismatch repair deficiency (Aaltonen et al., 1993; Papadopoulos et al., 1994; Wooster et al., 1994a; Yee et al., 1994).

Analysis of the highly polymorphic microsatellite loci not only provides information about MI, but also allows the detection of allelic deletion in tumor cells. Loss of heterozygosity can only be assayed in heterozygous loci. Tumor suppressor genes are generally inactivated by an intragenic mutation within one allele and the subsequent loss of the corresponding (wild) allele, resulting in a condition termed "loss of heterozygosity" (LOH) (Knudson, 1993). Somatic DNA alterations leading to $\mathrm{LOH}$ are generally more complex and may include multifocal deletion, mitotic recombination or nondisjunctional chromosomal loss, as well as gene conversion and point mutation (Meuth, 1990). The frequent allelic loss at particular chromosomal regions in tumors indicates the presence of a tumor suppressor gene.

Loss of heterozygosity and microsatellite instability are integral parts of neoplasmic progression. Analysis of this abnormality is of great significance for clinical diagnostics and is recommended in molecular screening for both inherited and sporadic neoplasms (Jass et al., 1995; Aaltonen et al. 1998).

This study reports a precise and efficient method for detecting microsatellite instability and $\mathrm{LOH}$ with the use of an automated fluorescent DNA sequencer. We used a well-characterized multiplex system enabling coamplification and typing of five short tandem repeats (STRs): HUMD1S103, HUMTH01, HUMD21S11, HUMD18S51, HUMFIBRA (FGA), and the amelogenin locus (MiścickaŚliwka et al., 1997). This system has been used in our laboratory in routine forensic and paternity investigations. This study presents its application in genetic analysis of 70 breast cancer specimens.

\section{MATERIALS AND METHODS}

DNA was extracted from blood and tumor tissue specimens collected from patients who were treated at the Regional Cancer Center in Bydgoszcz during the years 1997-1998. All 70 tumor samples were invasive ductal carcinomas (IDC). Tumor tissues were surgically resected and whole blood samples were obtained from corresponding patients through venipuncture. Biological samples was collected according to Approval of Independent Ethics Committee of the Ludwik Rydygier Medical University in Bydgoszcz. The tumor tissue was then snap-frozen in liquid nitrogen and stored at $-70^{\circ} \mathrm{C}$. Genomic DNA was extracted from tumor tissue and each corresponding whole blood sample using standard organic protocol (Sambrook et al., 1998). DNA concentration was measured using GeneQuant DNA Calculator (Pharmacia-Biotech Uppsala, Sweden).

Amplification of a hexaplex consisting of five STR loci (HUMD1S103, HUMTH01, HUMD21S11, HUMD18S51, and HUMFIBRA) and the amelogenin locus, HUMAMGXY, was performed according to previously described procedure (Miścicka- Śliwka et $a l .$, 1997). The amplified fragments were separated in $6 \%$ denaturing polyacrylamide gels on A.L.F Automated Fluorescent DNA Sequencer (Pharmacia Biotech, Uppsala, Sweden). External Size Standard 50-500 bp (Pharmacia Biotech) was used. An internal size standard was the shorter product of the amelogenin locus (106 bp). Fragment Manager software was used to measure size and signal intensity of the fluorescent PCR products. This software allows for automated linear quantitation and calculation of allelic ratios.

Statistical analysis was performed using $\chi^{2}$ tests and Fisher exact test with the "SPSS" statistical package. 


\section{RESULTS}

A multiplex PCR system was used to identify the expansion and/or deletion of five microsatellite loci: D1S103, TH01, D21S11, D18S51, and FGA, in tumor specimens. These loci were amplified from genomic DNA that had been extracted from tumor specimens and corresponding whole blood samples obtained from each patient. One fluorescent dye was used for simultaneous amplification of five STR sequences in a single reaction. The PCR products from the tumor and normal control tissue were then separated in two different lanes in the gel. We present a comparative analysis of many genetic profiles from corresponding normal and neoplasmic tissue samples and set up criteria for the assessment of $\mathrm{MI}$ and $\mathrm{LOH}$.

The electropherograms in Fig. 1 represent a genetic profile at five microsatellite loci (D1S103, TH01, D21S11, D18S51, FGA) and the AMG locus of normal lymphocyte DNA and tumor neoplasmic DNA collected from the same patient. Loss of heterozygosity was identified when either no peak or a very weak peak (signal for one of the alleles reduced by at least $35 \%$ ) was detected in the neoplasmic DNA as compared to the control lymphocyte DNA. Strength of the signal corresponding to an individual allele was defined by the software as peak height and peak area. To estimate the degree of $\mathrm{LOH}$, peak areas of the alleles in a heterozygote from normal $(\mathrm{N})$ and tumor sample ( $\mathrm{T}$ ) were calculated. However, one must take into account measurement errors or slight differences in the efficiency of PCR amplification. In this experiment, the relative difference in peak areas of normal heterozygotes was calculated to average $10 \%$ for all tested loci. For a few heterozygous STR loci, a higher imbalance of $25 \%$ was observed. We assumed $\mathrm{LOH}$ when $\geq 35 \%(25 \%+10 \%)$ differences between peak areas were encountered. All the results were verified by two independent PCR reactions.
The electropherograms in Figs. 1 and 2 show the relative amounts of the two corresponding alleles, indicating loss of heterozygosity. For example, in tumor samples the microsatellites D21S11 in lane 2 (Fig. $1 \mathrm{~A}, \mathrm{~B}$ ) and D1S103, D21S11 and FGA in lane 2 (Fig. 2 ), had very weak peaks at positions corresponding to the peaks of the normal allele. Therefore, $\mathrm{LOH}$ could be assessed and quantitated very effectively using the Fragment Manager software. Table D in Fig. 1, and E in Fig. 2 demonstrate software quantitation and calculation of allelic ratios at the analyzed heterozygous loci.

Microsatellite instability was identified when a novel allele in tumor DNA was observed as compared to the control lymphocyte DNA.

To measure the DNA fragment size precisely, fluorescently labeled external size markers (50-500 bp) were loaded into every fifth gel lane. An internal size marker was the shorter PCR product of the amelogenin locus (106 bp), coamplified with the five microsatellite loci and coelectrophoresed. The Fragment Manager software used the internal size standard to normalize electrophoretic mobility differences between lanes. In one-color analyses, cancer and normal DNA amplicons were labeled with the same dye and separated in two different lanes of the gel. In this system, the amplified DNA fragments were measured with an accuracy of one base pair. The case shown in lane 2 of Fig. 1 was classified as MI positive because a novel allele, which was 4 bp longer than the longest allele in the normal DNA, was identified at the FGA locus in the cancer DNA. The results of fragment sizing, as well as peak height and area measurements, are tabulated in Fig. 1D. Additionally, in MI positive microsatellites, the comparison of signal detection between normal and cancer DNA revealed a decrease in signal strength for one allele in cancer DNA. Thus, the presented system efficiently detected diverse types of microsatellite changes in cancer specimens. 


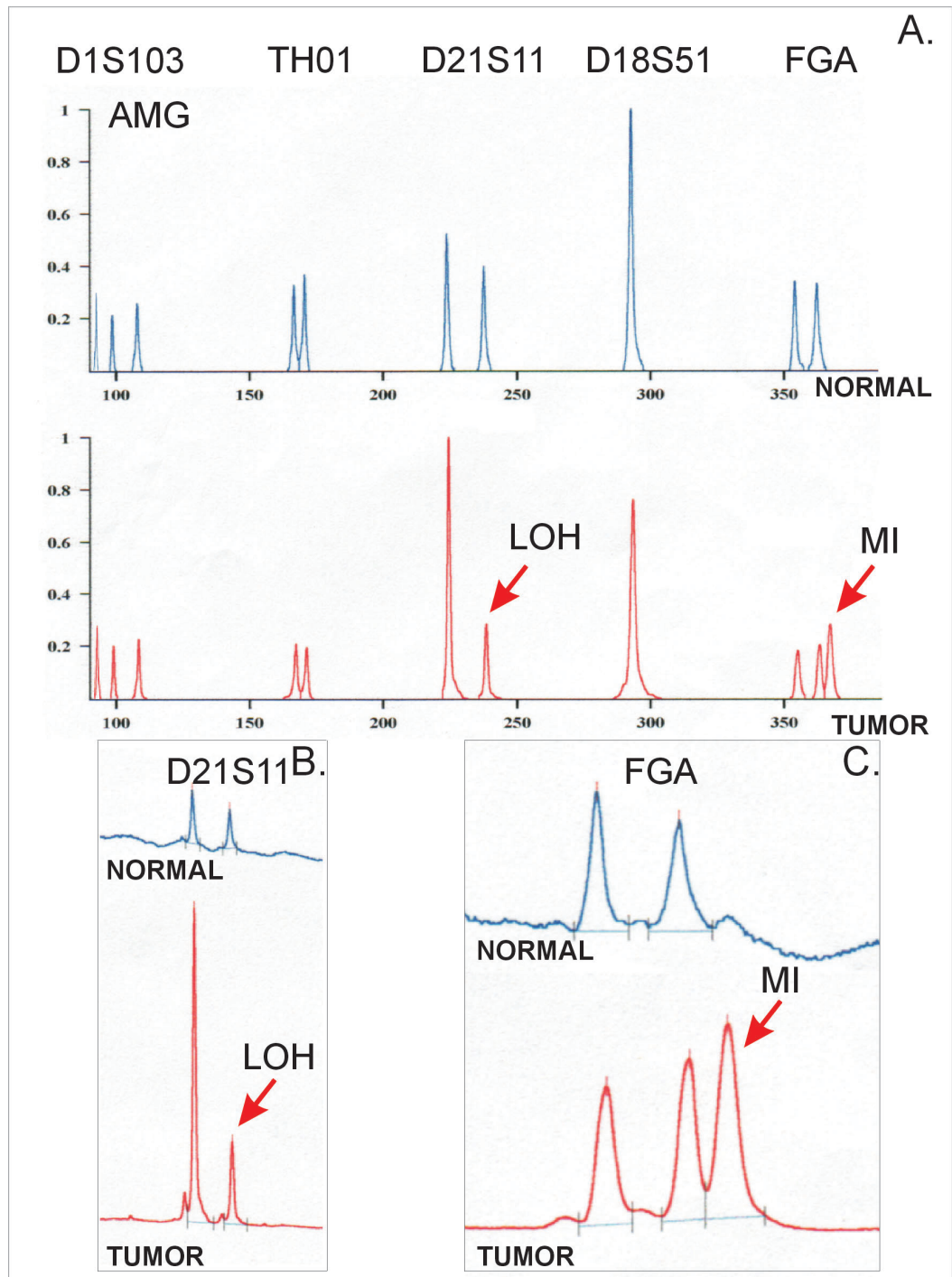

D.

Pharmacia DNA Fragment Manager V1.1

\begin{tabular}{|c|r|r|r|r|}
\hline Lane & Peak\# & Peak Height & Peak Area & Size (BP) \\
\hline NORMAL & 1 & $3.05 \%$ & 53.236 & 79.8 \\
\cline { 2 - 5 } & 2 & $2.11 \%$ & 43.615 & 96.1 \\
\cline { 2 - 5 } & 3 & $1.89 \%$ & 53.097 & $\propto 106.0$ \\
\cline { 2 - 5 } & 4 & $2.07 \%$ & 67.180 & 166.1 \\
\cline { 2 - 5 } & 5 & $2.28 \%$ & 75.186 & 169.8 \\
\cline { 2 - 5 } & 6 & $3.14 \%$ & 107.110 & 221.6 \\
\cline { 2 - 5 } & 7 & $2.31 \%$ & 81.514 & 235.6 \\
\cline { 2 - 5 } & 8 & $4.85 \%$ & 203.370 & 290.6 \\
\cline { 2 - 5 } & 9 & $1.90 \%$ & 69.646 & 351.9 \\
\hline TUMOR & 10 & $1.51 \%$ & 68.010 & 360.1 \\
\cline { 2 - 5 } & 1 & $47.39 \%$ & 902.92 & 79.7 \\
\cline { 2 - 5 } & 2 & $21.50 \%$ & 466.600 & 96.1 \\
\cline { 2 - 5 } & 3 & $19.42 \%$ & 525.180 & 0106.0 \\
\cline { 2 - 5 } & 4 & $12.27 \%$ & 484.370 & 166.3 \\
\cline { 2 - 5 } & 5 & $12.32 \%$ & 453.260 & 170.1 \\
\cline { 2 - 5 } & 6 & $64.82 \%$ & 2302.600 & 221.8 \\
\cline { 2 - 5 } & 8 & $16.97 \%$ & 656.440 & 236.0 \\
\cline { 2 - 5 } & 9 & $28.63 \%$ & 424.730 & 290.7 \\
\cline { 2 - 5 } & 10 & $9.23 \%$ & 474.950 & 352.5 \\
\cline { 2 - 5 } & 11 & $10.76 \%$ & 653.540 & 360.7 \\
\hline
\end{tabular}

Figure 1. An example of LOH and MI identified in carcinoma ductale invasivum mammae.

A. An electropherogram of hexaplex PCR reaction. Top lines show profile for STR D1S103, THO1, D21S11, D18S51, and FGA amplicons in control normal DNA (N, black). Bottom profile shows microsatellite instability in locus FGA detected in tumor DNA (T, red). Arrows indicate positions of allele alterations. B. Loss of heterozygosity in D21S11 locus is interpreted as reduced area of one allelic peak as compared to corresponding normal DNA. C. MI positive case in FGA locus, identified as additional peaks in tumor profiles. D. Results of Fragment Manager analysis, yellow lines indicate peaks representing changed alleles. 


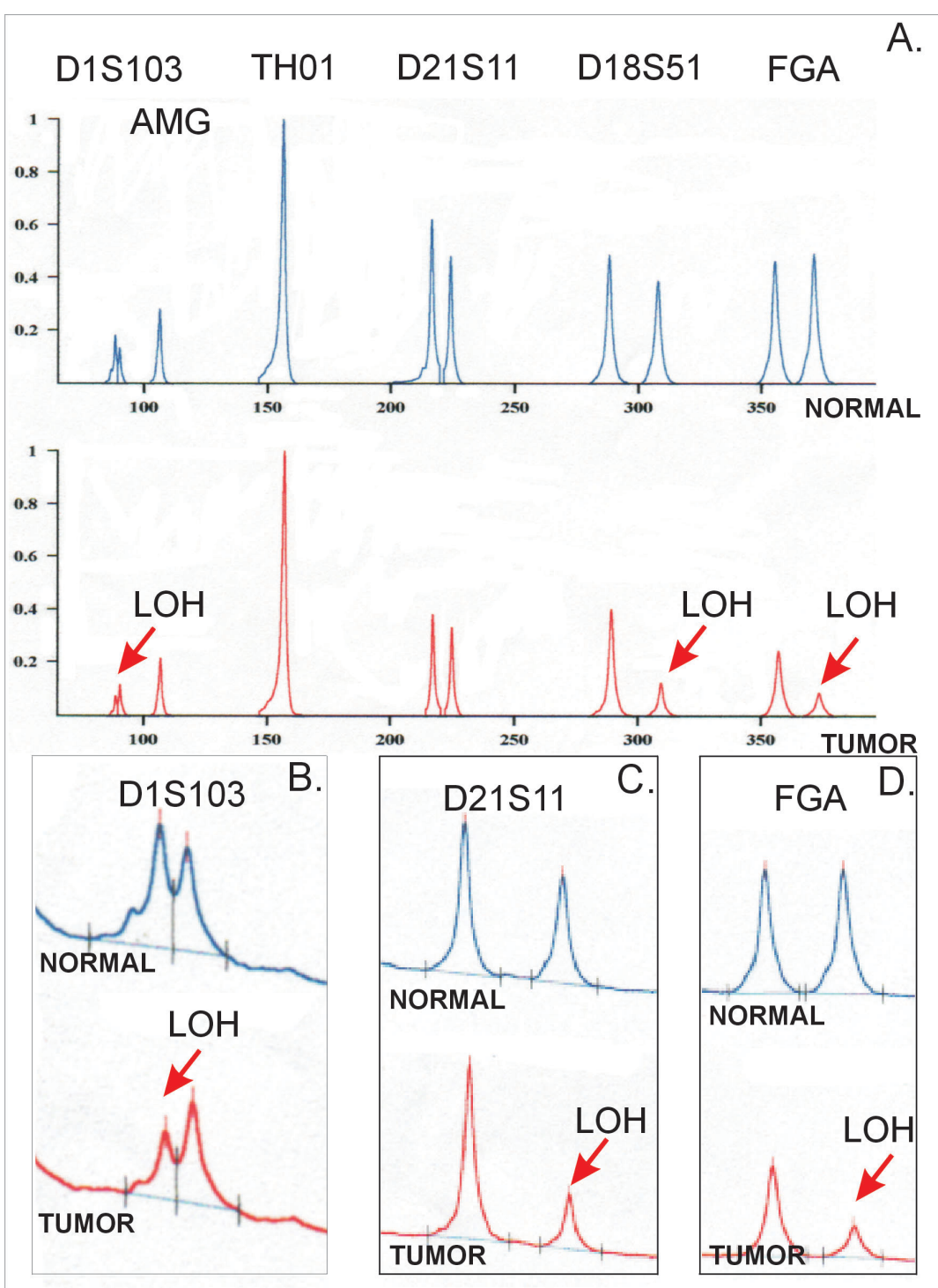

E.

Pharmacia DNA Fragment Manager V1.1

\begin{tabular}{|c|r|r|r|r|}
\hline Lane & Peak\# & Peak Height & Peak Area & Size (BP) \\
\hline NORMAL & 1 & $9.83 \%$ & 348.96 & 87.3 \\
\cline { 2 - 5 } & 2 & $8.27 \%$ & 255.38 & 89.1 \\
\cline { 2 - 5 } & 3 & $14.45 \%$ & 535.97 & 0106.0 \\
\cline { 2 - 5 } & 4 & $30.58 \%$ & 1896.30 & 155.6 \\
\cline { 2 - 5 } & 5 & $20.76 \%$ & 1176.70 & 215.9 \\
\cline { 2 - 5 } & 6 & $19.15 \%$ & 915.93 & 223.5 \\
\cline { 2 - 5 } & 7 & $11.53 \%$ & 926.78 & 287.5 \\
\cline { 2 - 5 } & 8 & $8.26 \%$ & 737.79 & 307.3 \\
\hline TUMOR & 9 & $9.41 \%$ & 879.62 & 354.8 \\
\cline { 2 - 5 } & 10 & $9.48 \%$ & 933.16 & 370.6 \\
\cline { 2 - 5 } & 1 & $6.64 \%$ & 196.67 & 87.8 \\
\cline { 2 - 5 } & 2 & $9.97 \%$ & 311.61 & 89.5 \\
\cline { 2 - 5 } & 3 & $15.85 \%$ & 573.33 & $@ 106.0$ \\
\cline { 2 - 5 } & 4 & $45.32 \%$ & 2655.00 & 156.1 \\
\cline { 2 - 5 } & 5 & $23.31 \%$ & 1015.70 & 216.5 \\
\cline { 2 - 5 } & 7 & $20.24 \%$ & 882.52 & 224.2 \\
\cline { 2 - 5 } & 8 & $13.61 \%$ & 1070.60 & 288.7 \\
\cline { 2 - 5 } & 9 & $6.26 \%$ & 332.70 & 308.9 \\
\cline { 2 - 5 } & 10 & $2.44 \%$ & 654.06 & 356.5 \\
\hline
\end{tabular}

Figure 2. An electropherogram of hexaplex PCR fluorescent analysis with multilocus $\mathrm{LOH}$.

A. Six microsatellite loci, D1S103, THO1, D21S11, D18S51, FGA, and AMG were simultaneously electrophoresed in a single lane, $\mathrm{N}$, normal (black); $\mathrm{T}$, tumor (red). B. A single locus with LOH. Faint peaks in the position of deleted alleles are interpreted as representing PCR products from normal tissue present in the tumor sample. E. Results of Fragment Manager analysis, red arrows indicate peaks representing changed alleles. 
Differences between tumor and normal DNA were detected in 34 out of 70 invasive ductal carcinomas (IDC) (48\%). In all, 78 alterations were detected in tumors, including microsatellite instability and loss of heterozygosity. In 26 cancer samples, changes in more than one locus were observed. In 70 IDC tumor cases, 6 (8\%) were identified with somatic microsatellite instability, and 31 tumors (44\%) with LOH. The results obtained are summarized in Table 1.

The potential impact of $\mathrm{MI}$ and $\mathrm{LOH}$ on tumor growth and progression of invasive ductal carcinoma was determined by simultaneous assessment of various parameters, including: patient's age, family history of breast cancer, condition of lymph nodes, and tumor grade and size (unpublished data). A statistically significant correlation was found between the occurrence of genetic alterations in microsatellites and the family history of breast cancer, patient age, and the presence of pathological lymph nodes $(P<0.05)$. No correlation was found with tumor size and grade $(P>0.05)$.

\section{DISCUSSION}

Loss of heterozygosity and microsatellite instability are integral parts of neoplastic progression, observed in hereditary nonpolyposis colorectal cancer (HNPCC) and other sporadic malignancies (Aaltonen et al., 1993; Papadopoulos et al., 1994; Wooster et al., 1994a; Yee et al., 1994). A rapid, reliable, and easy screening method is presented for the detection of $\mathrm{MI}$ and $\mathrm{LOH}$, based on a hexaplex PCR reaction routinely used in forensic and paternity studies. The fluorescence-based procedure does not require radioactive materials or special facilities and can be easily performed in any clinical laboratory. Six loci were amplified in one PCR reaction, using a 40 lane sequencing gel (with an external size marker loaded in every fifth lane) so that a maximum of 18 patients could be examined in one assay.

The Fragment Manager software was used to calculate the size, and peak height and area for each fluorescent product. This method enables detection of differences between neoplastic and normal tissue, providing an effective, sensitive, and accurate analysis of both MI and LOH. Previous reports point out to higher reliability of automatic fluorescent detection changes in STRs over the conventional radiolabeling methods (Toh et al., 1996; Wang et al., 1997).

The software enabled automated linear quantitation and calculation of allelic ratios, allowing rapid identification of LOH. Molecular analyses of allelic deletion remain difficult to interpret, as samples usually contain several subpopulations of tumor cells. Frequent mixtures of tumor samples and normal cells create further difficulties for accurate interpretation (Bièche \& Lidereau, 1995). The technique utilizing PCR reaction and electrophoretic separation provides a highly sensi-

Table 1. Results of the analysis of microsatellite instability and loss of heterozygosity in breast cancers

\begin{tabular}{llll}
\hline Locus & Chromosomal location & MI & LOH \\
\hline HUMD1S103 & lq32-44 & $3 / 70(4 \%)$ & $10 / 53(18 \%)$ \\
HUMTH01 & llpl5-15.5 & $0 / 70(0 \%)$ & $14 / 55(25 \%)$ \\
HUMD21S11 & $21 q 21$ & $0 / 70(0 \%)$ & $15 / 63(24 \%)$ \\
HUMD18S51 & $18 q 21.33$ & $1 / 70(1 \%)$ & $15 / 56(27 \%)$ \\
HUMFIBRA & $4 q 28-31$ & $2 / 70(2 \%)$ & $17 / 62(27 \%)$ \\
\hline
\end{tabular}


tive method for the detection of changes at microsatellite loci - a single neoplastic cell can be identified among 500 normal ones, as described by Sidransky (1997).

It was observed that the detection of $\mathrm{LOH}$ with the use of multiplex fluorescent PCR systems was effective in tumor tissue sections. For the system used in this study, optimal template DNA concentration is 5-10 ng per $25 \mu \mathrm{l}$ of $\mathrm{PCR}$ reaction volume (MiścickaŚliwka et al., 1997). It was found that template concentration outside the optimal range disturbed the accuracy of peak measurements for each fluorescent product and thus posed difficulties for the observation of microsatellite changes.

This highly discriminating multiplex system is sensitive enough for both personal identification and cancer cell detection. Herein described is a method for single-color detection on a single-wavelength automated DNA sequencer, which is much simpler in use than four-dye sequencers. The single-color detection system eliminates the problem of different detection sensitivities displayed by different dyes when using multi-wavelength sequencers such as ABI 373,377 or 310 . This is very important for the quantitation and calculation of allelic ratios, and facilitates measurement of allelic deletions in tumor DNA.

This study analyzed the cases of MI and $\mathrm{LOH}$ in microsatellites localized in five chromosomes. Alteration in the HUMFIBRA locus, located at $4 \mathrm{q} 28$, occurs frequently in invasive ductal carcinomas, which may suggest the importance of this chromosomal region for tumor growth (unpublished data). A high frequency of LOH detected in loci D18S51 and THO1 confirms the localization of the known suppressor genes DCC (18q) and TSG101 (11p15) in the vicinity of these loci (Fearon et al., 1990; Li et al., 1997).

Our recent study demonstrated also that genetic alterations in microsatellites are correlated with patient age and family history of breast cancer, as well as with the presence of pathological lymph nodes (unpublished data). Germinal mutations in the BRCA1 and/or $B R C A 2$ gene are responsible for the majority of hereditary breast cancer cases (Feunteun \& Lenoir, 1996; Sobczak et al., 1997; Wooster et al., 1994). Recent studies on their biological functions suggest a role in monitoring and/or repair of DNA lesions (Feunteun, 1998). Inactivation of these genes leads to genetic instability and increased mutation rate in some genes, such as the tumor suppressor genes controlling progression of the cell cycle. Our data and other studies (Aldaz et al., 1995; De Marchis et al., 1997; Sourvinos et al., 1997; Arzimanoglou et al., 1998) suggest that changes in microsatellites may predate to later mammary tumorogenesis.

The automated multiplex analysis of $\mathrm{LOH}$ and MI presented here can be a useful method for cancer screening (both inherited and sporadic) and has a potential prognostic value. In summary, the fluorescent multiplex technique of $\mathrm{MI}$ and $\mathrm{LOH}$ detection enables simultaneous assessment of changes in multiple loci in human tumors and has a wide range of potential applications in many clinical fields.

\section{R E F E R E N C E S}

Aaltonen LA, Peltomaki P, Leach FS, Sistonene P, Pylkkanen L, Mecklin JP, Jarvinen H, Powell SM, Jen J, Hamilton SR, Peterson GM, Kinzler KW, Vogelstein B, de la Chapelle A. (1993) Clues to the pathogenesis of familial colorectal cancer. Science.; $\mathbf{2 6 0}$ : $812-6$.

Aaltonen LA, Aslovaara MD, Kristo P, Canzian F, Hemminki A, Peltomaki P, Chadwick RB, Kaariainen H, Eskelinen MD, Jarvinen $\mathrm{H}$, Mecklin JP, Chapelle A. (1998) Incidence of hereditary nonpolyposis colorectal cancer and the feasibility of molecular screening for the disease. $N$ Engl J Med.; 338: 1481-7.

Aldaz CM, Chen T, Sahin A, Cunningham J, Bondy M. (1995) Comparative allelotype of in situ and invasive human breast cancer: 
high frequency of microsatellite instability in lobular breast carcinomas. Cancer Res.; 55: 3976-81.

Arzimanoglou II, Gilbert F, Barber HRK. (1998) Microsatellite instability in human solid tumors. Cancer.; 82: 1808-20.

Bièche I, Lidereau R. (1995) Genetic alteration in breast cancer. Genes Chromosomes Cancer.; 14: 227-51.

Bronner CE, Baker SM, Morrison PT, Warren G, Smith LG, Lescoe MK, Kane M, Earabino C, Lipford J, Lindblom A, Tannergard P, Bollag RJ, Godwin AR, Ward DC, Nodenskjold M, Fishel R, Kolodner R, Liskay RM. (1994) Mutation in the DNA mismatch repair gene homologue hMLH1 is associated with hereditary nonpolyposis colon cancer. Nature.; 368: 258-61.

De Marchis L, Contegiacomo A, D’Amico C. (1997) Microsatellite instability is correlated with lymph node-positive breast cancer. Clin Cancer Res.; 3: 241-8.

Fearon ER, Cho KR, Nigro JM, Kern SE, Simons JW, Ruppert JM, Hamilton SR, Preisinger AC, Thomas G, Kinzler KW. (1990) Identification of a chromosome 18q gene that is altered in colorectal cancer. $S c i-$ ence.; 247: 49-56.

Feunteun J. (1998) Breast cancer and genetic instability: the molecules behind the scenes. Mol Med Today.; 4: 263-7.

Feunteun J, Lenoir GM. (1996) BRCA1, a gene involved in inherited predisposition to breast and ovarian cancer. Biochim Biophys Acta; 1242: $177-80$.

Fishel R, Lescoe MK, Rao MR, Copeland NG, Jenkins NA, Garber J, Kane M, Kolodner R. (1993) The human mutator gene homolog MSH2 and association with hereditary nonpolyposis colon cancer. Cell.; 75: 1027-38.

Jass JR, Cottier DS, Jeevaratnam P, Pokos V, Holdaway KM, Bowden ML, Van de Water NS, Browett PJ. (1995) Diagnostic use of microsatellite instability in hereditary non-polyposis colorectal cancer. Lancet.; 346: 1200-1.
Knudson AG. (1993) Antioncogenes and human cancer. Proc Nat Acad Sci U S A.; 90: 10914-20.

Li L, Li X, Franke U, Cohen SN. (1997) The TSG101 tumor susceptibility gene is located in chromosome 11 band p15 and mutated in human breast cancer. Cell.; 88: 143-54.

Miścicka-Śliwka D, Grzybowski T, Woźniak M. (1997) Optimization of a hexaplex PCR amplification from Short Tandem Repeats (STR) and amelogenin (AMG) loci. Electrophoresis.; 18: 1627-32.

Meuth M. (1990) The structure of mutation in mammalian cells. Biochim Biophys Acta.; 1032: 1-17.

Papadopoulos N, Nicolaides NC, Wei YF, Ruben SM, Carter KC, Rosen CA, Haseltine WA, Fleischmann RD, Fraser CM, Adams MD, Venter JC, Hamilton SR, Petersen GM, Watson P, Lynch HT, Peltomaki P, Mecklin JP, de la Chapelle A, Kinzler KW, Volgelstein B. (1994) Mutaton of a mutL homolog in hereditary colon cancer. Science.; 263: 1625-9.

Risinger, JI, Barrett JC, Watson P. Lynch HT, Boyd J. (1996) Molecular genetic evidence of the occurrence of breast cancer as an integral tumor in patients with the hereditary nonpolyposis colorectal carcinoma syndrome. Cancer.; 77: 1836-43.

Sambrook J, Fritsch EF, Maniatis T. (1989) Analysis and cloning of eucaryotic genomic DNA. In Molecular cloning, a labolatory manual. pp 16-22. Cold Spring Harbor Laboratory Press.

Sidransky D. (1997) Nucleid acid-based method for the detection of cancer. Science.; 278: 1054-8.

Sobczak K, Kozłowski P, Napierała M, Czarny J, Woźniak M, Kapuścińska K, Łośko M, Koziczak M, Jasińska A, Powierska J, Braczkowski R, Bręborowicz J, Godlewski D, Mackiewicz A, Krzyżosiak W. (1997) Novel BRCA1 mutations and more frequent intron-20 alteration found among 236 women from Western Poland. Oncogene.; 15: 1773-9. 
Sourvinos G, Kiaris H, Tsikkinis A, Vassilaros S, Spandidos DA. (1997) Microsatellite instability and loss of heterozygosity in primary breast cancer. Tumor Biol.; 18: 157-66.

Toh Y, Oki E, Oda S, Tomoda M, Tomisaki S, Ichiyoshi Y, Ohno S, Sugimachi K. (1996) An integrated microsatellite length analysis using automated fluorescent DNA sequencer. Cancer Res.; 56: 2688-91.

Wang Y, Hung S, Linn JF, Steiner G, Glazer AN, Sidransky D, Mathies RA. (1997) Microsatellite-based cancer detection using capillary array electrophoresis and energy-transfer fluorescent primers. Electrophoresis.; 18: 1742-9.

Wooster R, Cleton-Jansen AM, Collins N, Mangion J, Cornelis RS, Cooper CS, Gusterson BA, Ponder BA, von Deimling A,
Wiestler OD. (1994) Instability of short tandem repeats in human cancer. Nat Genet.; 6: $152-6$.

Wooster R, Neuhausen SL, Mangion J, Quirk Y, Ford D, Collins N, Nguyen K, Seal S, Tran T, Averill D, Fields P, Marshall G, Narod S, Lenoir GM, Lynch H, Feunteun J, Odevilee P, Cornelisse CJ, Menko FH, Daly PA, Ormiston W, McManus R, Pye C, Lewis CM, Cannon-Albright LA, Petro J, Ponder BAJ, Skolnik MH, Easton DF, Goldgar DE, Stratton MR. (1994) Localization of a breast cancer susceptibility gene, BRCA2, to chromosome 13q12-13. Science.; 265: 2088-90.

Yee CJ, Roodi N, Verrier CS, Parl FF. (1994) Microsatellite instability and loss of heterozygosity in breast cancer. Cancer Res.; 54: 1641-4. 